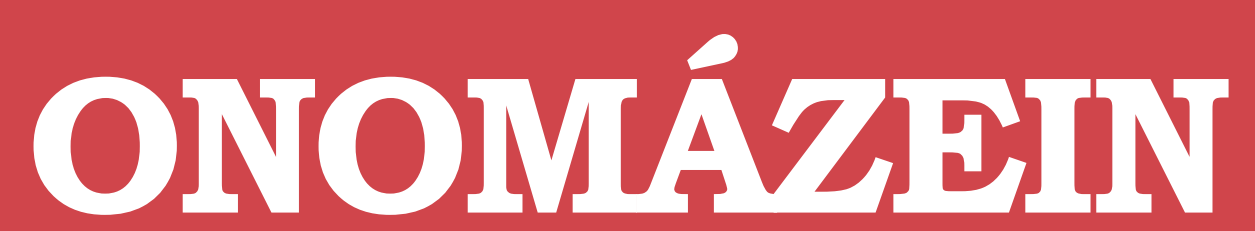

Revista semestral de lingüística, filología y traducción
PONTIFICIA UNIVERSIDAD

\title{
Normatividad, descripción y autoridad en la lingüística chilena: Voces usadas en Chile (1900) de Aníbal Echeverría y Reyes*
}

Normativity, description and authority in

Chilean linguistics: Voces usadas en Chile (1900)

by Aníbal Echeverría y Reyes

\author{
Darío Rojas \\ Universidad de Chile \\ Chile
}

\section{(c) (1) $\Theta$}

Darío Rojas: Departamento de Lingüística, Facultad de Filosofía y Humanidades, Universidad de Chile, Chile | Correo electrónico: darioroj@u.uchile.cl 


\section{Resumen}

El tránsito del siglo XIX al XX es un momento clave para la historia de los estudios lingüísticos en Chile: a la corriente tradicional normativista se superpone una tradición científica descriptivista inaugurada por Rodolfo Lenz y Federico Hanssen en la última década deI XIX. Voces usadas en Chile, de Aníbal Echeverría y Reyes, publicado en el 1900, refleja la tensión causada por el contacto entre ambas corrientes de estudios lingüísticos. Conviven en esta obra aspectos normativos y descriptivos, que responden a distintos horizontes de legitimidad vinculados con conflictos de autoridad idiomática. Mostramos que Echeverría y Reyes, a pesar de tener a Lenz como uno de sus modelos, no logra abandonar completamente la ideología de la lengua estándar, de modo que el normativismo es prevalente en su obra.

Palabras clave: lingüística chilena; historiografía lingüística; ideologías lingüísticas; norma lingüística.

\section{Abstract}

The transition from the $19^{\text {th }}$ to the 2oth century is a key moment in the history of linguistics in Chile: a traditional normativist trend met a scientific, descriptivist trend inaugurated by Rudolf Lenz and Friedrich Hanssen in the 1890s. Voces usadas en Chile, by Aníbal Echeverria y Reyes, published in the year 1900, reflects the clash between both trends of linguistic studies. In this work, normative and descriptive aspects coexist, each belonging to different horizons of legitimacy linked to conflicts of idiomatic authority. We show that Echeverría y Reyes, despite having Lenz as one of their models, does not completely abandon the ideology of the standard language, so normativism is prevalent in his work.

Keywords: Chilean linguistics; linguistic historiography; language ideologies; linguistic norm.

* Este trabajo se enmarca en el proyecto FONDECYT Regular 1150127 "Ideas lingüísticas en los debates sobre léxico y ortografía en Chile (1875-1927)", del cual el autor es investigador responsable. 


\section{Introducción}

Suena raro hablar de una "lingüística chilena” antes de la llegada de Rodolfo Lenz y Federico Hanssen a Chile, a fines del siglo XIX. El término lingüística fue acuñado a comienzos de ese siglo (primero en alemán: Linguistik), y su difusión y adopción fueron relativamente lentas (Swiggers, 2011). A Chile, al parecer, el término llegó primero refiriéndose específicamente a la filología histórico-comparada europea: Francisco Solano Asta-Buruaga publicó en 1874, en la revista Sud-América, un texto de divulgación titulado "Idea de la lingüística o ciencia del lenguaje", en el que "habla de las doctrinas de Max Müller, de Gmo. D. Whitney, de Benjamín W. Dwight y de Juan Fiske", así como de "Lorenzo Hervás, y de lo que esta ciencia debe a los hermanos Schlegel, a Carlos Gmo. Humbolt, a Francisco Bopp, a Jacobo L. Grim, a Agustín F. Pott” (Rojas Carrasco, 1940: 243).

A pesar de lo anterior, es evidente que hubo estudios del lenguaje en Chile antes de la llegada de los alemanes, y bastantes, como muestra el amplio catálogo bibliográfico aportado por Rojas Carrasco (1940). La particularidad de esos estudios es su carácter "precientífico", usando el calificativo que Matus (1994) aplica a la lexicografía chilena del periodo. La postura más común en los autores de entonces era el normativismo, entendido este como el estudio del lenguaje destinado a promover una norma o un estándar que se considera, por diversas razones, superior a otras variedades de lenguaje. Por esta razón, puede verse en estos autores, en mayor o menor medida (Avilés y Rojas, 2014; Rojas, 2014), la adhesión a una ideología lingüística prevalente en el mundo moderno, que Milroy (2001) Ilama ideología de la lengua estándar. Esta se caracteriza por la aspiración a imponer uniformidad sobre un objeto inherentemente variable, como es el lenguaje. Como consecuencia del deseo de supresión de la variedad, se llega a considerar que solo una de las variantes o variedades coexistentes es legítima o correcta. Esta es la variante o variedad estándar, que es considerada como parámetro de calidad de todas las conductas idiomáticas, que serán, así, mejores/ peores, correctas/incorrectas, bonitas/feas, etc., en la medida en que se acerquen o se alejen, respectivamente, del estándar. En el caso específico del mundo hispanohablante chileno, esta ideología motivó una actitud muy negativa hacia el habla local ("En Chile se habla muy mal") y una actitud positiva hacia un modelo exógeno, específicamente de impronta peninsular castellana, que fue el que se adoptó como modelo normativo. Al normativismo de los estudios lingüísticos chilenos se contrapuso, al terminar el siglo, la postura descriptivista, no valorativa, de autores como Rodolfo Lenz, quien, de hecho, revindicó el estudio científico de las variedades no estándar (Bernaschina, 2013).

En el presente artículo estudiaremos, desde un punto de vista complejo (una historiografía lingüística de inclinación antropológica, que re-

1 La historiografía lingüística tiene por objeto dar cuenta científicamente de cómo el conocimiento acerca del lenguaje ha sido obtenido y cómo este conocimiento ha cambiado o se ha mantenido a lo largo de la historia (Swiggers, 2012). En este contexto, por conocimiento se entiende lo opuesto a creencia, es decir, se hace referencia a las ideas aceptadas como válidas y "ciertas" acerca del lenguaje en determinado momento: el conocimiento "científico" aportado por la hoy denominada lingüística. En este sentido, la historiografía lingüística se propone reconstruir, en relación estrecha con su contexto sociohistórico, intelectual, político y económico, las concepciones del lenguaje que en momentos determinados fueron expresadas por determinados miembros de la sociedad: Ios especialistas. Sin embargo, la consideración de la influencia de la ideología y las actitudes en los discursos "especializados" acerca del lenguaje conlleva una relativización del valor de verdad o neutral que normalmente se atribuye a las descripciones científicas de los lingüistas, y contribuye a cuestionar la visión de la lingüística como una actividad sociopolíticamente aséptica. Es esta última postura la que adoptamos. 
curre al concepto de ideología lingüística² como principal herramienta analítica), la obra Voces usadas en Chile, de Aníbal Echeverría y Reyes, publicada en el año 1900. Este libro, debido al momento en que se publica y a las circunstancias de su autor, refleja la tensión causada por el encuentro entre normativismo y descriptivismo en los estudios lingüísticos chilenos. Conviven en esta obra aspectos normativos y descriptivos, que responden a distintos horizontes de legitimidad vinculados con conflictos de autoridad idiomática. Mostraremos, sin embargo, que Echeverría y Reyes, a pesar de tener a Lenz como uno de sus modelos, no logra abandonar completamente la ideología de la lengua estándar, de modo que el normativismo termina siendo prevalente en su obra.

Estudios monográficos anteriores sobre la obra de Echeverría, como el de Alfero y otros (2008) y el capítulo de Becerra y otros (2009), no han abordado en profundidad el problema particular del que se ocupa nuestro estudio, ni tampoco consideran los aspectos lingüísticoideológicos subyacentes; se ocupan más bien de cuestiones de técnica lexicográfica. De esta manera, nuestro estudio contribuirá a ampliar el conocimiento de este interesante hito de la historia lingüística chilena de fines del XIX.

\section{Generalidades sobre el autor y la obra}

El abogado Aníbal Echeverría y Reyes, nacido en Santiago en 1864 y muerto en la misma ciudad en 1938, hijo del héroe de guerra José Echeverría Lazo, fue sobre todo, según Feliú Cruz (1969), un aficionado a la bibliografía jurídica que mostró además un gran interés por el lenguaje, las lenguas y la literatura. Estudió Derecho en la Universidad de Chile y se recibió de abogado en 1886, aunque ya algunos años antes había comenzado a ocupar puestos administrativos en el Ministerio del Interior, bajo la presidencia del liberal José Manuel Balmaceda (1886-1891). En 1890 fue nombrado Juez de Letras, primero en Talcahuano y después (1891) en San Bernardo. Tras la caída de Balmaceda en la revolución de 1891, Echeverría fue destituido de sus cargos, por lo cual se mudó a Valparaíso para ejercer su profesión. Sin embargo, "más que a ella, se dedicó, con sus conocimientos legales, a la defensa de los militares dados de baja, enjuiciados y procesados por el nuevo régimen" (Feliú Cruz, 1969: 4). En 1905 se mudó a Antofagasta, en el norte de Chile, para seguir ejerciendo, esta vez sin compromisos políticos, la abogacía.

Los intereses intelectuales de Echeverría quedan reflejados, en primer lugar, en la variedad de sociedades y academias a las que perteneció: la Academia Chilena de la Lengua (como miembro correspondiente), el Ateneo de Santiago y la Sociedad Chilena de Historia y Geografía (de la cual fue miembro fundador), por nombrar solo algunas del ámbito local. En segundo lugar, fue un colaborador habitual de periódicos y revistas científicas como el Diario Oficial, El Mercurio (de Santiago y de Antofagasta), los Anales de la Universidad de Chile y la Revista Chilena, entre otros. Por último, escribió numerosos libros y folletos, principalmente bibliografías, pero también tratados sobre aspectos históricos, jurídicos, administrativos e, incluso, de salud pública.

En cuanto a su afición lingüística, Echeverría no solo se interesó por la lengua española. En 1890 publicó Noticias sobre la lengua atacameña y en 1896, en colaboración con Emilio Vaïsse, un Glosario de la lengua atacameña, obras en que se ocupó de esta desaparecida lengua indígena del norte de Chile conocida hoy como kunza o

2 Entendemos, con Kroskrity (2010), que una ideología lingüística es un conjunto de creencias y concepciones acerca del lenguaje, planteado de manera explícita o manifestado en prácticas comunicativas, que sirve a una comunidad para racionalizar el uso lingüístico y que a menudo responde a sus intereses políticos y económicos, sea los de la totalidad de sus miembros o los de grupos sociales determinados. 
likan-antay. También publicó un trabajo en que recogía "Datos sobre los jeroglíficos de la Isla de Pascua”, en 1910. Por último, en 1889 había publicado una bibliografía sobre el mapudungún, titulada La lengua araucana. Notas bibliográficas, en que hace un inventario crítico de las obras pertinentes de los padres Molina, Vega, Garrote y Torrellas, Valdivia, Febrés y Havestadt, y en que, marginalmente, da referencias sobre las lenguas indígenas pampa y yagán.

El español, su lengua materna, sin embargo, concentró gran parte de sus publicaciones lingüísticas, empezando por la bibliografía crítica Sobre lenguaje. Disquisición bibliográfica, de 1887, que sería la base de la bibliografía incluida entre los preliminares de Voces usadas en Chile. En 1895 publicó su Prontuario de ortografía castellana y en 1897 Nociones de ortografía casteIlana. Tras un trabajo cumulativo de varios años (véase la sección siguiente), publicó en 1900 Voces usadas en Chile. Su labor lexicográfica se prolongaría hasta sus últimos años de vida: en 1929, cuando ya estaba asentado en Antofagasta, aparece su Voces usadas en la industria salitrera, uno de los primeros diccionarios de voces técnicas publicados en Chile, que tendría una reedición, con varias supresiones, enmiendas y adiciones, en 1934, bajo el nombre Vocablos salitreros (editado esta vez en Santiago por la Universidad de Chile). Asimismo, en 1931 apareció su Vocabulario del Ingenioso Hidalgo don Quijote de la Mancha compuesto por Miguel de Cervantes Saavedra.

De entre estas obras, Voces usadas en Chile, la obra que nos ocupará en esta ocasión, sobresale tanto por su volumen como por la influencia que ejercería en los estudios lingüísticos chilenos de las décadas siguientes.

Este trabajo de Echeverría ha sido objeto de estudio tanto por parte de críticos contemporáneos como por parte de investigadores actuales, bien de modo individual o bien en el marco de la producción lexicográfica de la época (Becerra y otros, 2007; Alfero y otros, 2008; Chávez, 2009;
Rojas, 2010). La obra mayor de Echeverría es considerada un repertorio lexicográfico sui generis dentro de las obras lingüísticas escritas en Chile entre fines del XIX y comienzos del XX, pues presenta algunas características que le dan mayor "cientificidad" en comparación con la obras de Zorobabel Rodríguez, por ejemplo. Entre sus contemporáneos, esto le valió alabanzas: el mismo Rodolfo Lenz señaló que Voces usadas en Chile "es un notable progreso por el arreglo mas científico i la separacion limpia entre la crítica gramatical i la lexicolójica” (Lenz, 1987 [19051910]: 62). También le valió fuertes críticas, específicamente por haber incluido voces tabuizadas (y que guardan dicho valor hasta hoy) como pico 'pene' o culear 'tener sexo'.

Diversos estudios actuales sobre los diccionarios chilenos decimonónicos coinciden en caracterizar Voces usadas en Chile como una obra en que coexisten dos perspectivas o propósitos. Primero, una intención descriptiva, manifestada en el intento de dar una visión general del uso del español en el Chile de la época y en la inclusión de voces tabuizadas en la nomenclatura; segundo, un propósito normativo, bajo cuya influencia el autor propone erradicar galicismos, barbarismos y otros usos que considera impropios. La presencia de un elemento descriptivo en su obra ha llevado a concluir que se trata de una obra adelantada a su época, especialmente en comparación con contemporáneos representativos del prescriptivismo decimonónico. Asimismo, se la ha considerado como el hito que marca la transición hacia una lexicografía de corte más científico, en el marco de la periodización de la producción diccionarística chilena propuesta por Matus (1994). Sin embargo, el carácter descriptivo que diferencia el trabajo de Echeverría de los de otros autores ha sido colegido más bien de sus secciones introductorias y no de lo que se puede apreciar en el conjunto de las entradas que lo conforman.

Varios de los estudios sobre Voces usadas en Chile, casi sin vacilaciones, atribuyen a la in- 
fluencia de Lenz el "cientificismo" que le subyace y otras cualidades valoradas positivamente (Becerra y otros, 2007; Alfero y otros, 2008; Chávez, 2010). Esta interpretación se fundamenta, además de en el hecho obvio de que el filólogo alemán revisó el manuscrito de la obra (como queda consignado en su informe al Consejo de Instrucción Pública, que Echeverría incluyó como preliminar en la versión definitiva de su trabajo), en una correlación temporal entre la llegada de Lenz a Chile (junto con Federico Hanssen) y una transformación en la manera de estudiar el lenguaje en este país (Sand, 1958).

Dicha conclusión ha sido matizada por los hallazgos de Rojas (2011a) acerca de la participación de Lenz en Voces usadas en Chile, basados en 43 cartas de Echeverría a Lenz que se conservan inéditas en el Archivo Lenz de la Universidad Metropolitana de Ciencias de la Educación (Santiago, Chile). Efectivamente, el filólogo alemán fue una figura gravitante en la elaboración de esta obra. De acuerdo con las cartas, desde un comienzo Echeverría solicitó la participación del lingüista alemán como revisor, y consideraba su propio trabajo como parte integrante de una obra mayor en que las ideas ortográficas de Lenz jugaban un papel central. Sin embargo, esta es una influencia que Lenz ejerció más bien como modelo o referente en cuanto a la orientación descriptivista que asume Echeverría como propia. Lenz, al parecer, nunca llegó a interesarse mucho por la obra de Echeverría, o no hasta el punto de intervenir directamente en ella.

Las cartas de Echeverría a Lenz, adicionalmente, revelan varios detalles respecto de la elaboración de Voces usadas en Chile, entre los que destaca la manera en que el autor concibió originalmente la obra. Echeverría tenía ya preparado en 1894 un vocabulario de más de 2000 palabras (casi la mitad de la versión final). Lo interesante es que el autor concibió esta sección de su trabajo como parte integrante de una obra mayor que aglutinaba también los trabajos en que Lenz había expuesto ese mismo año sus ideas ortográficas (Lenz, 1894a y 1894b) y que tenía como eje al Diccionario ortográfico de José Manuel Marroquín. Este proyecto frustrado se ajusta al propósito pedagógico que tenían la mayor parte de los trabajos lingüísticos de la época. El carácter apendicular y no autónomo del "Vocabulario", de cualquier modo, tendrá reflejo en la versión final de Voces usadas en Chile, pues conformará una de las secciones de la obra mayor y no una obra independiente.

\section{Ideología y actitud lingüística en Vo- ces usadas en Chile}

La mayor parte del discurso lingüístico-ideológico de Voces usadas en Chile se encuentra concentrado en las secciones preliminares. En cambio, la sección "Voces", que corresponde a la parte sustancial del libro (cuantitativa y cualitativamente), contiene mucho menos discurso analizable de acuerdo con nuestro objetivo, Io cual presenta un fuerte contraste con otros repertorios chilenos contemporáneos.

Compárese, a modo de ejemplo, la misma entrada léxica en el diccionario de Rodríguez, por un lado, y en el de Echeverría, por el otro:

\section{AVALANCHA.}

Mui buscado por los poetas principiantes. Es palabra francesa, i tan desvergonzada, que apenas si ha tomado la precaucion de mudar en a la e con que termina en aquella lengua para penetrar en los dominios de la nuestra.

Es tanto más urjente desterrarla, cuanto que, teniendo en castellano alud y lurte, maldita la falta que nos hace. (Rodríguez, 1875)

AVALANCHA.-g.-f.-alud, lurte, gran masa de nieve que se derrumba de los montes a los valles. (Echeverría y Reyes, 1900)

Echeverría normalmente se limita a entregar de manera regular una explicación semántica (que se ajusta mayoritariamente al modelo aristotélico de definición) y/o un equivalente, 
junto con emplear en todos los artículos una marca que indica el tipo de vocablo del que se trata (chilenismo, galicismo, neologismo, barbarismo, etc.) y una marca que indica su categoría gramatical, siempre en un orden determinado y siguiendo estrictamente las convenciones indicadas en su sección preliminar. En este sentido, puede decirse que la sección lexicográfica de Voces usadas en Chile presenta mayor condensación textual lexicográfica (Bustos Plaza y Wiegand, 2005-2006) que otros diccionarios chilenos de su época.

Según nuestro parecer, lo anterior no significa, sin embargo, como han pensado algunos investigadores (véase la sección anterior), que no existan valoraciones normativas del lenguaje en los artículos lexicográficos de Voces usadas en Chile. En el ejemplo anterior, puede apreciarse que existe una marca que implica la atribución del vocablo avalancha a una categoría claramente evaluativa, como es la de "galicismo". Para interpretar adecuadamente esta información, por supuesto, debemos tener en cuenta lo que Echeverría dice en el "Prólogo" de la obra acerca de los galicismos (que revisaremos más adelante). Las prácticas definitorias también pueden ser reveladoras respecto de valoraciones lingüísticas: piénsese, por ejemplo, en la diferencia entre entregar un sinónimo, implícitamente sugiriendo su uso en lugar de la voz definida, y hacer una definición analítica de tipo aristotélico (volveremos sobre esta diferencia más adelante). En consecuencia, nuestro análisis deberá abordar tan- to los paratextos como el texto nuclear de Voces usadas en Chile ${ }^{3}$.

Entre los textos preliminares de esta obra, hay un breve paratexto que merece comentario: la dedicatoria. Echeverría escribe: "A la Real Academia Española dedica este trabajo El AutoR". Con ello, ya anuncia el horizonte normativo que sustenta su ideal de lengua. Varios años más tarde, en 1916, la Academia Chilena de la Lengua Io nombrará su miembro correspondiente por Antofagasta (Araneda 1976), en lo que podría interpretarse como un reconocimiento institucional al alineamiento lingüístico-ideológico de Echeverría. Las referencias a la RAE se repiten en el "Prólogo". En él, el autor señala explícitamente el Diccionario de la RAE (en su edición de 1884) como parámetro de contrastividad 4 para determinar si ciertas palabras usadas en Chile son provincialismos, neologismos, arcaísmos, etc., "aunque algunas estan contenidas en los trabajos de Salvá, Dominguez, Zerolo etc." (Echeverría y Reyes, 1900: XV).

Echeverría califica positivamente al Diccionario de la RAE con frases como "obra monumental" y "Léxico oficial". Una de las finalidades de Voces usadas en Chile, dice su autor, es "apuntar las voces nuevas que merecen admitirse en el Diccionario" (Echeverría y Reyes, 1900: Xx), lo cual es congruente con el "academiocentrismo" propio de los diccionarios hispanos (Seco, 2003) y, en particular, con la dependencia de la lexicografía hispanoamericana decimonónica respecto de la lexicografía académica (Chuchuy, 1994)5.

3 A pesar de lo expuesto, no faltan ejemplos, escasos por cierto, de valoraciones normativas manifestadas explícitamente en los artículos lexicográficos por Echeverría y Reyes, como el siguiente, en que aparece la modalización deóntica del decir a través del verbo deber: "DESEMBARQue.-b.-m.-tratándose de personas, debe decirse desembarco".

4 En Rojas (2011b) se muestra cómo Echeverría y Reyes, en las observaciones contrastivas que incluye en 24 de los cerca de 4000 artículos de la sección "Voces”, atrae intertextualmente de manera bastante evidente al Diccionario académico. Por ejemplo, si el DRAE de 1884 define el americanismo bochinchero como 'alborotador, alterador de la tranquilidad pública', Echeverría y Reyes observa que dicha palabra significa 'el que promueve o se mezcla en bochinches, aún cuando no alborote o altere la tranquilidad pública’ (resalte nuestro). Igualmente, si el DRAE de 1884 señala que cambullón es un peruanismo (usando la marca "Per.") en el sentido de 'enredo, trampa', Echeverría y Reyes comenta que "no sólo es peruanismo" (1900: S. v.).

5 Para el caso de los diccionarios chilenos, véase Rojas (2010: 227-228), donde se explica el carácter intertextual de estos repertorios. 
En la sección de "Observaciones jenerales", por otra parte, aparece una frase ideológicamente aún más explícita que las anteriores, en cuanto reconoce no solo un valor referencialdescriptivo en la institución madrileña, sino que también le concede autoridad lingüístico-normativa: "La autoridad a que nos hemos atenido para determinar la correccion o incorrección de las voces, es la Real Academia Española” (Echeverría y Reyes, 1900: 24).

El "Informe" que aparece al comienzo de Voces usadas en Chile muestra cuál es la otra autoridad que Echeverría reconoce y quiere atraer para legitimar su texto: la de las ciencias del lenguaje, encarnadas institucionalmente en la Facultad de Filosofía, Humanidades y Bellas Artes de la Universidad de Chile (que por entonces cumplía el papel de una especie de Ministerio de Educación) e individualmente en la figura de Rodolfo Lenz. Echeverría consiguió publicar Voces usadas en Chile como anexo de los Anales de la Universidad de Chile. Para obtener este beneficio, el autor debió solicitarlo formalmente al Consejo de Instrucción Pública. Este organismo delegó en Rodolfo Lenz y Antonio Diez, miembros de la Facultad de Filosofía, la elaboración de un informe respecto de los méritos del trabajo de Echeverría. Desde un primer momento, de hecho, Echeverría había comprometido la ayuda de Lenz, como se puede ver en las cartas que el abogado le envió al filólogo alemán durante el proceso preparatorio de la publicación.

La valoración que el informe, firmado por Lenz y Diez, hace de Voces usadas en Chile es positiva en lo general, gracias a lo cual el Consejo de Instrucción Pública admitió la publicación de la obra a expensas de fondos estatales. Vale la pena destacar, considerando el propósito de nuestra investigación, que Echeverría haya decidido copiar este informe de manera íntegra a manera de preliminar de Voces usadas en Chile. La autoridad que se vislumbra en este informe llega a exceder el ámbito puramente científico, pues, gracias al acucioso detalle de la transcripción, se presenta a los ojos del lector, prácticamente, una copia fiel del acta de la sesión del 21 de agosto de 1899 del Consejo de Instrucción Pública, en la que se decidió aceptar la publicación del libro a expensas del erario fiscal. Echeverría cita el contenido de esta acta directamente del número 6393 del Diario Oficial chileno, publicado el 6 de septiembre de ese mismo año. La autoridad político-educativa, de este modo, también aparece como fundamento de legitimidad de la obra. Los nombres que aparecen mencionados en el acta materializan esta autoridad: Diego San Cristóbal, rector de la Universidad de Chile, y "Ios consejeros Amunátegui [Domingo Amunátegui Solar, decano de la Facultad de Filosofía por ese entonces], Espejo, Montt, Toro, Varas, Zegers y el Secretario Jeneral Dr. Espejo" (Echeverría y Reyes, 1900: VII).

El alineamiento ideológico de Echeverría con la autoridad de la ciencia lingüística, en este respecto, también se puede apreciar cuando, en el capítulo segundo "Cambios fonéticos", explica que la aspiración chilena de la /s/ implosiva "sucede, sin duda, por influencia del araucano que no tiene tal sonido" (Echeverría y Reyes, 1900: 28), frase con que alude y adhiere a la conocida hipótesis araucanista de Rodolfo Lenz.

Pero, además, hay una sección macroestructural completa dedicada a exponer el sustento científico de la obra de Echeverría: la "Bibliografía”. El autor, como buen bibliógrafo, disponía al parecer de una abundante colección de obras dedicadas a los estudios del lenguaje. En la "Bibliografía" expone ordenadamente, de acuerdo con criterios dialectológicos (primero por subcontinentes y luego por países) y normativos (pone como subsección aparte de la bibliografía la de obras dedicadas a la "Corrección del lenguaje”), las obras que le sirvieron de apoyo. Entre las obras dedicadas al español de Chile (el país que tiene más referencias: 34), cabe destacar que muchas de ellas no son meras descripciones dia- 
lectológicas, como podría hacer pensar el que no se incluyan en la sección de "Correcciones"

La sección bibliográfica de "Correcciones del lenguaje" es más extensa, con mucha ventaja, que cualquiera de las dedicadas a algún país (contiene 76 referencias), y lo que le da su especificidad es precisamente que contiene obras dedicadas a la lengua española concebida como entidad desterritorializada: un español estándar general, que, sin embargo, muestra una inclinación hacia la península ibérica, pues la mayoría de las obras fueron publicadas en España por autores españoles?. El examen de estas obras ayuda a dar una idea de los instrumentos en que se apoyó Echeverría para discriminar entre usos correctos e incorrectos: gramáticas, diccionarios generales y diccionarios ortográficos, de sinónimos o de ideas afines, así como diccionarios de galicismos. Nótese además que varias de estas obras tienen un carácter histórico o etimológico (Mayans y Siscar, Monlau), por lo cual puede pensarse que Echeverría consideraba, como otros autores de su época, que el uso apropiado dependía del criterio de la autoridad clásica, esto es, dependía de los autores de una etapa que se consideraba clásica o más perfecta, o bien, en otros casos, que tuvo como referente una etapa considerada "castiza" de la lengua (castellano medieval, en Mujica) o la etapa clásica (Ximénez de Embun y Val), o bien que usaban como criterio la etimología, para asuntos como la mantención de la $h$ en la ortografía. Vaya a saber uno, en cualquier caso, si realmente Echeverría tuvo tiempo de leer todas estas obras: quizá incluyó muchas en su bibliografía solo para alardear de fundamentos científicos para su propia obra.

En el "Prólogo", Echeverría explica el propósito de su obra: "Hace tiempo concebimos la idea de coleccionar gran número de vocablos impropios i locuciones incorrectas usados en Chile" (Echeverría y Reyes, 1900: xiii). Si cruzamos esta afirmación con los datos que Rojas (2011a) muestra acerca del proceso de creación de Voces usadas en Chile, la conclusión evidente es que la intención primera y original de la obra era claramente normativa, y seguía fielmente el propósito de la tradición lexicográfica chilena del siglo XIX iniciada por Gormaz y continuada luego por Zorobabel Rodríguez y otros. Echeverría señala que "además", de manera complementaria, recoge neologismos que merecen ser aceptados en el estándar (volveremos sobre esto en las secciones siguientes). Sin embargo, unas líneas más adelante, el orden jerárquico de los propósitos se invierte:

6 Echeverría incluye, por ejemplo, el catálogo anónimo de 1843 (Ferreccio, 1979), las Correcciones lexigráficas de Gormaz (1860), el Diccionario de Rodríguez (1875) (junto con los reparos a esta obra por Del Solar [1876] y la respuesta de Paulsen [1876]) y el de Ortúzar (1893), es decir, el núcleo mayor de la lingüística normativa chilena precedente, dedicada precisamente a correcciones de lenguaje. Por otra parte, también incluye los “Ensayos filológicos americanos” de Rodolfo Lenz, que sí corresponden a un afán científico descriptivo.

7 En este grupo se encuentran, entre las obras lexicográficas, el Diccionario de la lengua castellana de la Real Academia Española (en su edición de 1884), el Diccionario de construcción y régimen de Rufino José Cuervo (1886-1893), el Diccionario enciclopédico de la lengua castellana de Elías Zerolo, Miguel de Toro y Garcés y Emiliano Isaza (1895), el Diccionario etimológico de la lengua castellana de Pedro Felipe Monlau (1881), el Diccionario de galicismos de Rafael María Baralt (1890) y Sinónimos castellanos de Roque Barcia (1890). Entre las obras gramaticales, la Gramática de la lengua castellana de la Real Academia Española (en la 20. a edición de 1895), la Gramática de la lengua castellana de Pedro Martínez López (1850), la Gramática filosófica de la lengua española de José Segundo Flórez (1856), la Primera gramática española razonada de Manuel M. Díaz (1889-1892), la Gramática de la lengua castellana según ahora se habla de Vicente Salvá (1895), la Gramática de la lengua castellana destinada al uso de los americanos de Andrés Bello (en la edición anotada por Cuervo de 1898). También incluye una serie de obras de índole lingüístico-histórica, tales como Formación de la lengua española de Roque Barcia (1872), Orígenes de la lengua española de Manuel Mayans y Siscar (1875), la Gramática del castellano antiguo de Pedro de Mujica (1891) y Lengua española en el siglo de oro de su literatura de Tomás Ximénez de Embun y Val (1897). Asimismo, se cuentan algunas otras obras didáctico-normativas, tales como el Diccionario ortográfico de Manuel J. Marroquín (1882), Cizaña del lenguaje de Francisco J. Orellana (1891), el Arte de hablar en prosa y en verso de José Gómez de Hermosilla (1893) y el Diccionario de la conjugación castellana de Emiliano Isaza (1897). 
Nuestro propósito, ajeno a toda pretension de suficiencia, fué primariamente formar un Vocabulario Chileno, si así fuere exacto espresarnos, en cuyas pájinas pudiera ser relativamente conocido por los que se dedican a estudios sobre lingüística americana, el uso que actualmente se hace en Chile de la lengua castellana; i, despues, esponer, a los que por ignorancia incurren en los vicios de lenguaje apuntados, cuáles son las dicciones propias i cuáles los modos correctos de decir correspondientes a cada impropiedad o incorreccion. (Echeverría y Reyes, 1900: xiv; resalte nuestro)

La misma jerarquización de fines, expresada por el uso del marcador discursivo ante todo, se ve en el siguiente pasaje, esta vez espigado de las "Observaciones jenerales":

Procuramos en este trabajo recojer todas las espresiones vulgares, tanto las desterradas de la sociedad culta como las aceptadas por ella, no para criticarlas i condenarlas únicamente, sinó, ante todo, con el objeto de dar una idea de las particularidades del lenguaje del pueblo i del castellano de Chile en jeneral. (Echeverría y Reyes, 1900: 23; resalte nuestro)

Coexisten, por tanto, como han apuntado otros estudiosos de la obra de Echeverría (Alfero y otros, 2008; Matus, 1994), un propósito claramente normativo, mostrar variantes chilenas incorrectas y sus correspondientes equivalentes estándares, con otro que tiene tintes más descriptivos, como es el dar cuenta del uso que se hace en Chile de la lengua castellana.

Según nuestro parecer, estos propósitos se solapan y, aún más, suelen darse de manera simultánea. En la sección lexicográfica de Voces usadas en Chile, incluso cuando Echeverría simplemente está exhibiendo, por ejemplo, un neologismo, sin que aparezcan valoraciones explícitas, está realizando igualmente un acto performativo de tipo normativo, de acuerdo con el planteamiento de Rojas (2010). Considérense los siguientes ejemplos:
ACHICHARRAR.-b.-v.-achuchar, aplastar.

VOCERÍO.-n.-m.-vocería, gritería.

En ambas entradas existe idéntico grado de condensación textual y se usa el mismo recurso definitorio (la equivalencia). Sin embargo, achicharrar es etiquetado como un barbarismo (b.), categoría censurada por Echeverría, mientras que vocerío recibe la calificación de neologismo (n.), categoría que Echeverría considera aceptable (véanse los párrafos siguientes). Es decir, en el primero hay un acto de proscripción idiomática (de comprobación, en términos de Rojas (2010)), mientras que en el segundo se trata de una prescripción (refutación, según Rojas). Aunque las actitudes lingüísticas de estos ejemplos son completamente divergentes, ambas se fundamentan en un modelo cultural (una ideología lingüística) que supone que hay algunos usos que son correctos (como vocería) y otros que son incorrectos (como achicharrar) y, por tanto, en ambos casos hay valoraciones normativas. La condensación textual mayor en comparación con la de la obra de, por ejemplo, Zorobabel Rodríguez da una impresión de asepsia valorativa que en realidad no es tal.

La obra de Echeverría, en conclusión, tiene un carácter fundamentalmente normativo, Io cual es congruente con su contexto y lo cual se condice, además, con la manera en que lo interpretaron sus críticos (véase Rojas y Avilés, 2012).

Véase, por último, la manera en que el autor, casi al finalizar el "Prólogo", sintetiza los objetivos de su obra, en una enumeración que puede interpretarse también en términos de prioridades:

En resúmen, el objeto de nuestra tarea, difícil e ingrata de suyo, es poner a la vista los vocablos impropios que en Chile se usan; dar su equivalente en castellano o lijerísimas definiciones de aquellas palabras cuyo significado no es bastante conocido; indicar los vicios que adulteran la hermosa fonética de nuestro idioma; disminuir, en lo que factible fuere, las incorrecciones de 
lenguaje, hablado o escrito i, por fin, apuntar las voces nuevas que merecen admitirse en el Diccionario. (Echeverría y Reyes, 1900: Xx)

La operación de "exponer" o "exhibir", que parece la imagen favorita de Echeverría para caracterizar su propia obra (véase la frase poner a la vista en la cita anterior), tiene dos aristas, relacionadas con los propósitos antes mencionados. Primero, debe considerarse que el hecho de exponer, sin necesariamente valorar de forma explícita, en este y en otros repertorios normativos de la época, parece seguir la lógica del know your enemy: para separar el trigo de la paja, digamos, primero es necesario conocer bien el conjunto. Es, entonces, una exposición que apoya la denuncia fundada.

Da la impresión, además, de que el análisis detallado a través del cual Echeverría atrae para su obra la autoridad de la ciencia tiene también la finalidad de diseccionar minuciosamente el sector del organismo que se pretende extirpar, con lo cual el lector interesado puede conocer en profundidad la conducta que no debe imitar. No se trata de un análisis lingüístico destinado a mostrar la regularidad o lógica de los fenómenos en cuestión, evidentemente. Nótese lo que acabamos de comentar en el siguiente pasaje, donde aparecen lexías valorativas referidas a la conducta idiomática, tales como vicio, afear, purificar, incorrección, impropio, violar, dañar y viciar:

Al tomar nota de las palabras que denominamos barbarismos, nos llamó la atencion la copia de vicios prosódicos que afean nuestro modo de decir; i consultando siempre la idea de purificar nuestro lenguaje, juzgamos de notoria conveniencia dar á conocer en detalle esas incorrecciones. Con este fin i para no dilatar sin causa justificada la estension del Vocabulario, elimina- mos de éste aquellos barbarismos fonéticos para considerarlos por separado, dejando en él, sólo las dicciones reprensibles por vicios ortográficos i analójicos, o por acepciones impropias.

Hemos distribuido los barbarismos fonéticos en verbales, o que violan la conjugacion, los que son abundantisimos i dañan a fondo el mecanismo de nuestras múltiples inflecciones verbales, i en jenerales, que afectan a toda clase de palabras.

Los barbarismos que vician la fonética de nuestra conjugación, estan espuestos en un órden i forma que, sin ser ni aun aproximadamente perfectos, creemos consultan cierta claridad i concurren á comprender el mayor número de casos en la menor estension posible. (Echeverría y Reyes, 1900: xvii-xviii)

Los barbarismos fonéticos a los que se refiere Echeverría son tratados en el capítulo sobre "Cambios fonéticos", bajo una minuciosa clasificación: distingue entre "alteraciones jenerales", que pueden aparecer en a) consonantes o b) vocales (véanse los ejemplos de más adelante), y "cambios fonéticos particulares" (custión por cuestión), "cambios ortográficos" (zelo por celo), "metátesis" (catredal por catedral) y "acentuación” (mastíl por mástil). Dentro de los barbarismos fonéticos generales incluye rasgos como el debilitamiento de /s/ implosiva (ra'juñar por rasguñar, con ensordecimiento de la consonante siguiente) o incluso en comienzo de palabra (eñor por señor), la neutralización de líquidas implosivas (farta y pelcha por falta y percha), reducción de grupos consonánticos cultos (dotor por doctor o afeuto por afecto), es decir, rasgos fonéticos del vernáculo chileno que tienen continuidad hasta la fecha actual.

El exponer, en segundo lugar, atañe también a las voces que merecen ser aceptadas en opinión de Echeverría, y en este punto se revela el

8 Los que se distinguen por ser "ménos jenerales, mas aislados, i que son debidos a asimilaciones o disimilaciones, o a la fuerza de la analogía, o a etimologías populares o falsas” (Echeverría y Reyes, 1900: 41). 
carácter complementario del DRAE que también tiene Voces usadas en Chile, y que lo convierte parcialmente en una herramienta codificadora del estándar hispánico local:

Es mui importante hacer notar las voces nuevas que merecen admitirse, para no caer en el conocido círculo vicioso de que el uso no las introduce, porque la Real Academia Española no las ha autorizado, i que tan alta Corporacion no las acepta, por cuanto aquel no las ha favorecido. (Echeverría y Reyes, 1900: xvi)

La convivencia de una faceta normativa con otra un poco más descriptiva alcanza ribetes de conflicto al incluir Echeverría una serie de voces que de seguro en el Chile de fines del XIX tenían el carácter de tabuizadas, y que etiqueta como "chilenismos vulgares". Estos refieren fundamentalmente a genitales (culo, choro, chucha, poto, 'vulva'; chincol, chulloca, diuca, pájaro, perforador, pico, picha, pichula 'pene'; huevos 'testículos', etc.) y a distintos conceptos relacionados con la sexualidad, en general (polvo 'coito'; chuño 'semen'; culear 'yacer con mujer'; etc.). Echeverría supone que el incluir estas palabras le costará fuertes críticas (así fue, como veremos más adelante), de modo que en el "Prólogo" se justifica por adelantado:

En nuestra obra figuran diversos vocablos o locuciones que algunos pudieran tachar de indecorosos u obscenos. Les hemos dado cabida por dos razones: desde luego, por juzgar que todo trabajo literario, cualquiera que sea su objeto, no envuelve intrínsicamente idea alguna nociva o vituperable, siempre que se concrete a enseñar la verdad; i en segundo término, porque dar a conocer en detalle las diversas voces proferidas constantemente en una determinada rejion, exije fidelidad completa de esposicion, esto es, no omitir ninguna y precisar su significado; a no ser ello exacto, todos los Léxicos merecerian, en lo que a decencia de lenguaje respecta, la fea nota de inmoralidad o de ocasionados a pervertir costumbres. Fijar el valor propio de dicciones que incluyen desdorosos conceptos, no se encamina a sujerir ideas contrarias a la nobleza de espresion, ni mucho menos recomendar el empleo de aqueIlas: labor semejante es sólo el reconocimiento de un hecho. Ningun saber humano es inmoral: llega a serlo cuando su aplicacion es ilejítima. (Echeverría y Reyes, 1900: xxi-xxii)

Nótese que en esta cita Echeverría usa expresiones como "enseñar la verdad", "fidelidad completa de exposición" y "reconocimiento de un hecho", con lo cual toca el aspecto descriptivo de su obra, pero también habla de "fijar el valor propio" de estos vocablos mediante su exposición, con lo cual igualmente se entremezcla la función normativa, incluso en estos vocablos que supuestamente constituyen el índice más claro del descriptivismo de Echeverría.

En el prólogo, el autor pone mucho énfasis en las categorías lexicológicas que distingue desde un punto de vista normativo. Lo interesante, desde un punto lingüístico-ideológico, es que establece dos categorías mayores en que quedan subsumidas todas las demás. Primero, "vocablos impropios i locuciones incorrectas usados en Chile" (Echeverría y Reyes, 1900: xiii). Los tipos de vocablos que recubre esta categoría son: 1) barbarismos, 2) extranjerismos (sobre todo galicismos) y 3) "incorrecciones que contradicen abiertamente la gramática de nuestro idioma" (Echeverría y Reyes, 1900: xiii). Segundo, exentos de esta valoración quedarían los neologismos usados por las capas cultas de la población, que, según el parecer del autor, "tienen derecho a ser incorporados en nuestra lengua" (Echeverría y Reyes, 1900: xiii).

La "aceptación” e "incorporación” de estos neologismos, por supuesto, para Echeverría pasa por el reconocimiento de la RAE a través de su inclusión en su Diccionario. La necesidad de que la RAE incorpore estas voces tiene relación, en primer lugar, con la naturaleza misma del lenguaje, que el autor caracteriza como fundamentalmente dinámica: el idioma no puede "encasiIlarse en reglas fijas, indiferentes a la evolución 
del progreso" (Echeverría y Reyes, 1900: xv). En este punto, Echeverría hace un interesante excurso en que exhibe una visión biologicista del lenguaje afín a la que había expuesto décadas antes August Schleicher (1821-1868) y que ya casi era asumida como sentido común por la época en que escribe nuestro autor (Bynon, 2000):

El idioma, como es sabido, es un verdadero organismo sujeto a las leyes de la vida, i, como tal, tiene que amoldarse en su desarrollo al movimiento perfectivo social i no permanecer en dañosa estagnacion, pues asi corre peligro de morir. (Echeverría y Reyes, 1900: xv)

En segundo lugar, la necesidad de incorporar estas voces se relaciona con una especie de condición "seudodemocrática" que Echeverría postula respecto de la participación de los hispanohablantes en la definición de los límites del modelo ideal de lengua, afirmación que tiene obvias reminiscencias de un famoso pasaje ${ }^{9}$ de la Gramática de Bello:

No es posible que una enorme cantidad de individuos que en el Nuevo Mundo hablan el casteIlano, no tenga derecho a que se admitan oportunamente como propios, sus peculiares vocablos, en atencion al medio en que viven, pues esa franquía la tienen los provincialismos de Aragon, Andalucia etc. (Echeverría y Reyes, 1900: Xv)

Es, en nuestra opinión, una propuesta "seudodemocráctica" porque, al igual que en las ideas de Andrés Bello (Moré, 2004) y otros intelectuales de la época (Avilés y Rojas, 2014; Rojas, 2014), la participación en la política lingüística y la preeminencia en materia del buen uso quedan reservadas para las personas cultas. Recuérdese que la aceptación de los neologismos chilenos quedaba justificada por ser usados entre personas educadas. Echeverría llega a declarar abiertamente que "el vulgo jamas podrá dar el tono de un idioma” (Echeverría y Reyes, 1900: xv). Más adelante, en las "Observaciones jenerales", se refiere a la capa culta de la población, metafóricamente, como un territorio geopolítico del cual se deben "desterrar" las expresiones vulgares (Echeverría y Reyes, 1900: 23). En el capítulo sobre "Cambios fonéticos", diferencia entre un fenómeno aceptable por ser general entre todas las capas sociales, como el yeísmo, y un fenómeno sujeto a actitud negativa, como es el debilitamiento de la /s/ implosiva, que Echeverría considera "mas vulgar, i solo propia de Chile" (Echeverría y Reyes, 1900: 27). De hecho, el vocabulario que usa este autor para hablar de este fenómeno es revelador de su actitud hacia él:

Esta s, que el pueblo casi ha suprimido, se pronuncia con tanta mayor perfeccion cuanto mas elevada es la posicion social del individuo: sin embargo nunca se oye pronunciar con toda perfeccion como en el Perú. El guaso dice eñor o simplemente ñor, aunque no pronunciar la s entre vocales o al principio de palabra solo es propio de la jente mas atrasada. (Echeverría y Reyes, 1900: 28; resalte nuestro)

La razón de este trato preferencial para el habla de las personas educadas, al parecer nuevamente radica en la suposición de que la intervención en el destino del idioma debe ser guiada por principios, leyes, por algo que asegure un orden en el marco del progreso, lo cual idealmente puede ser aportado por personas instruidas. Nuestro autor señala que no es conveniente, en materia de lenguaje, "independizarse de todo cuerpo docente", ni que "el Diccionario de la Academia contenga cuanto el común de la jente acepta sin exámen, por capricho o versatilidad" (Echeverría y Reyes, 1900: Xv). La referencia a la "índole del idioma" aparece acá como el principal criterio determinador de la aceptabilidad de los neologismos. Y la razón última de que deba

9 "Chile y Venezuela tienen tanto derecho como Aragón y Andalucía para que se toleren sus accidentales divergencias" (Bello, 1847: xii). 
ponerse cuidado en esto es la preservación de la unidad de la lengua española, que "[puede] al dejenerarse [...], producir dialectos especiales, que seran caricaturas de la hermosa lengua castellana” (Echeverría y Reyes, 1900: xvi).

Volviendo a las categorías lexicológicas normativas que distingue Echeverría, más adelante precisa otras subcategorías, que fundamentan las marcas valorativas que incluirá en la sección lexicográfica de su libro:

Hemos distribuido los vocablos en la forma siguiente:

Chilenismos, voces que se usan pura i esclusivamente en este pais.

Americanismos, palabras que se emplean entre nosotros i por la mayor parte de los que habitan este Continente.

Neolojismos, dicciones cuya admision es conveniente, sea porque corresponden a derivaciones o inflecciones correctas, o porque se refieren a objetos o ideas no definidos en el Léxico oficial.

Arcalsmos, voces que figuran como anticuadas en el Diccionario de la Academia, pero de las que nos servirnos cotidianamente apesar de que en España ya no se usan.

Estranjerismos inútiles, por tener en castellano dicciones de significacion análoga.

Galicismos insoportables, que merecen señalarse con especialidad para evitar que, por su empleo diario, se arraiguen en el lenguaje; i

Barbarismos, faltas que consisten en adicionar, suprimir o permutar letras o sílabas, alterar la verdadera acentuacion, el jénero o el número, o en atribuir acepciones impropias a voces castizas. (Echeverría y Reyes, 1900: xvi-xvii)

Solo algunas de estas categorías reciben valoraciones explícitas. Por un lado, la categoría de neologismo queda asociada con la corrección idiomática y es objeto de valoración positiva. Por otro lado, Echeverría califica a ciertos extranjerismos de "inútiles" (e incorrectos, por tanto, a diferencia de otros que sí cubren una necesidad denominativa, se entiende), a los galicismos de "insoportables" y se refiere a los barbarismos como "faltas" que "alteran lo verdadero" y caen en el terreno de lo "impropio".

En cuanto a los barbarismos, Echeverría emplea en su tratamiento una práctica lexicográfica que materializa discursivamente su carácter percibido de "alteraciones" o sustituciones: definiciones que empiezan con por e indican luego el ítem léxico que debería usarse. Es decir, en el fondo, una estructura que se asemeja a la organización normativo-discursiva del Appendix Probi, mediante la cual se muestra que dichos vocablos se usan en lugar de otra cosa, que es la que debería estar, y que, por lo tanto, hay una relación de exclusión mutua, lo cual es completamente coherente con la ideología de la lengua estándar. Un par de ejemplos:

Mohosear.-b. o.-v.-por mohecer.

Volido.-b.-m.-por vuelo, acción de volar.

Este recurso se usa también para otras categorías, pero lo revelador es la proporción: en las definiciones de barbarismos se usa 195 veces, de un total de 552 ítems (35,3\%), mientras que, por ejemplo, en las definiciones de neologismos se usa solo 9 veces en 977 posibilidades (0,9\%).

Cumplen una función similar las definiciones encabezadas por "En el sentido de", que también remite a los recursos textuales de Gormaz, y que se usa en proporción menor que la fórmula anterior: 32 veces en los barbarismos (5,7\%) y solo una vez para un neologismo (0,1\%):

Alción.-b.-f.-en el sentido de acción.

LLANA.-n.-f.-en el sentido de palustre, paleta que usan los albañiles [...].

Volviendo a la cita precedente, ¿qué sucede, entonces, en la ideología de Echeverría, con los chilenismos, los americanismos y los arcaísmos, que aparecen presentados, en la cita, de manera aparentemente neutral? Para responder a esta pregunta, es necesario interpretar en relación con otras secciones de este paratexto, así como con el propio texto lexicográfico de Voces usadas en Chile. 
En cuanto a los chilenismos y americanismos, podría pensarse, sobre la base del pasaje antes citado en que se evoca la defensa bellista del "derecho al provincialismo", que Echeverría valora positivamente estas categorías. Sin embargo, en el referido pasaje el autor alude específicamente a los neologismos. Podría pensarse que chilenismo y americanismo son entendidos por Echeverría como tipos específicos de neologismos, pero ¿por qué entonces distingue entre tres categorías y no establece ninguna relación taxonómica entre ellas? De hecho, en las entradas lexicográficas de la sección "Voces", las marcas correspondientes a estas categorías se dan de manera disyuntiva: una palabra o es neologismo, o es chilenismo, o es americanismo; no hay tal cosa como un "chilenismo neológico". No es posible, en conclusión, suponer a partir de ese dato que Echeverría muestra una actitud positiva hacia el provincialismo americano o chileno.

Otro elemento de juicio al respecto se encuentra en las "Observaciones jenerales", donde el autor hace una subclasificación de los chilenismos:

No emplean un mismo lenguaje todos los individuos que hablan un idioma comun: no habla lo mismo el labriego que el individuo de sociedad, ni espresa de igual manera sus ideas el hombre que ha recibido escasa instruccion que el que la ha recibido sólida i completa. Por esto, al hablar de chilenismos o particularidades de nuestro lenguaje, tenemos que distinguir aquellos que podríamos llamar chilenismos cultos, i que usa corrientemente en la escritura i en la conversacion la jente educada, de aquellos que debemos llamar vulgarismos, porque son propios del bajo pueblo. Es cierto que la clase culta conoce esta segunda clase de chilenismos, pero no los usa sino ocasionalmente en el lenguaje festivo o en la conversacion familiar. Una tercera categoría de chilenismos la constituye lo que nosotros llamaremos ultra-correcciones. Comprende las voces que emplean las personas medio instruidas, que forman una clase social que se conoce con el nombre de «jente de medio pelo». Los individuos de esta clase; pretendiendo alejarse del lenguaje del bajo pueblo, imitan el de la clase culta; pero como no tienen instruccion suficiente, lo imitan mal. (Echeverría y Reyes, 1900: 24-25)

Podemos inferir, teniendo en cuenta la preeminencia que el autor otorga al habla de las personas cultas, que el primer tipo de chilenismos, los "chilenismos cultos", son considerados aceptables por Echeverría. El concepto de vulgarismo tiene asociada una connotación negativa, lo que se puede deducir del movimiento retórico defensivo de las capas cultas: estos no usarían tanto estas palabras, es decir, no abusan tanto de estas "malas palabras". La causa, probablemente, es que se trataría de palabras que aluden a realidades que las "personas decentes" evitarían nombrar: en la sección "Voces” encontramos marcadas como chil. vulg. una serie de palabras tabuizadas, que ya hemos mencionado. Reveladoramente, entonces, las capas bajas de la población son conceptualizadas negativamente por Echeverría, primero, desde el punto de vista moral; lo lingüístico (el uso profuso de esas malas palabras) no sería más que una manifestación ulterior de esa condición del espíritu. La ultracorrección, por último, aparece conceptualizada abiertamente como una manifestación de ignorancia y de incompetencia idiomática, con lo cual es objeto de actitud negativa. Curiosamente, esta tripartición de la categoría chilenismo no tiene reflejo directo en las marcas, aunque podría asumirse que la marca ch., sin mayores especificaciones, hace referencia a los chilenismos cultos, mientras que la marca más específica ch. vulg., como es evidente, indica los vulgarismos; pero la ultracorrección no tiene su marca específica. De hecho, este último fenómeno es tratado exclusivamente en el capítulo "Cambios fonéticos", de manera que ninguna entrada de la sección "Voces" corresponde a una ultracorrección. 
Como ya habíamos mencionado, las prácticas definitorias de Echeverría podrían ser consideradas pistas respecto de sus actitudes hacia ítems léxicos particulares así como hacia categorías lexicológicas completas. Grosso modo, el autor hace tres tipos de definiciones: analíticas (Alambrado-am.-m.-cerco de alambre afianzado con postes), sinonímicas (Vilote.-ch.-adj.-cobarde) y mixtas (FInANCIERo--n.-adj.-rentístico, lo relativo a la Hacienda Pública). Para efectos de nuestro análisis, distinguiremos entre las definiciones en que se ofrece un equivalente (sinonímicas y mixtas) y aquellas en que no se ofrece tal (analíticas). Las primeras, según nuestra interpretación, implícitamente recomiendan sustituir el uso del lema por el equivalente ofrecido, de manera que implican una valoración negativa del ítem que funciona como lema. Esta interpretación tiene apoyo, entre otros, en la proporción con que ocurren las definiciones con equivalente en dos categorías claramente valoradas negativamente por Echeverría, como son los barbarismos y los galicismos. En la tabla I puede verse claramente la abrumadora predominancia de definiciones con entrega de equivalente en estas dos categorías.

Los ítems pertenecientes a las primeras dos categorías son objeto de actitud negativa, de modo que Echeverría, en su afán pedagógico, señala cuál es la alternativa castiza o "correcta".

¿Qué sucede, en este mismo respecto, con los neologismos? Como puede verse también en la tabla I, la tendencia opuesta a la que acabamos de ver no se cumple: a pesar de que los neologismos son valorados positivamente por Echeverría, este no usa mayoritariamente defini- ciones analíticas en sus correspondientes artículos lexicográficos. De hecho, en casi la mitad de los artículos en que se describen neologismos, igualmente se ofrecen equivalentes de uso. Podría pensarse que los neologismos, entonces, no son tan bien valorados por Echeverría como él mismo declara abiertamente, o al menos no todos. O bien que, a pesar de su legitimidad, Echeverría cree conveniente indicar de todos modos cuál es el equivalente de uso reconocido en la norma. O bien, por último, que la entrega de un equivalente funciona como recurso facilitador para que el lector entienda rápidamente a qué refiere dicha palabra, más que como una práctica con connotación normativa.

Vemos, en conclusión, que, aunque en las categorías valoradas negativamente en el prólogo Echeverría muestra una clara preferencia por la entrega de equivalentes al describirlas en cada artículo lexicográfico, no sucede lo contrario en las categorías valoradas positivamente.

En la explicación de chilenismos y americanismos, como se puede ver en la tabla I, Echeverría muestra una leve preferencia por ofrecer equivalentes, pero nunca tan acusada como la que mostraba en el caso de barbarismos y galicismos.

Es difícil, ciertamente, sacar conclusiones tajantes a partir de las tres últimas columnas de la Tabla antes referida. No pensamos que esa ventaja de las equivalencias en las categorías de chilenismo y americanismo pueda interpretarse como una inclinación a valorar negativamente estas categorías. Más bien, creemos que su perfil se asemeja al de los neologismos. Para el caso de

\section{TABLA 1}

Tipos de definiciones en distintas categorías léxico-normativas usadas por Echeverría y Reyes (porcentajes)

\section{BARBARISMO}

GALICISMO

CHILENISMO

AMERICANISMO NEOLOGISMO

\begin{tabular}{lccccc}
\hline Sin equivalencia & 8,3 & 12,8 & 38,9 & 44,6 & 52,3 \\
\hline Con equivalencia & 91,7 & 87,2 & 61,1 & 55,4 & 47,7 \\
\hline
\end{tabular}


Ios chilenismos, sabemos que Echeverría considera que algunos son aceptables (los chilenismos cultos), mientras que otros no. Para el caso de los americanismos, sin embargo, no tenemos igual posibilidad de profundizar en la actitud que Echeverría tenía hacia dicha categoría.

\section{Conclusión}

A pesar del descriptivismo aparente de Voces usadas en Chile, varios datos dan cuenta de que su autor, en gran medida, compartía la orientación lingüístico-ideológica de autores contemporáneos tales como Zorobabel Rodríguez. De hecho, la concepción misma de la obra parte de un propósito didáctico-normativo, como puede verse en las cartas que Echeverría envió a Lenz. En el "doble propósito" declarado en el prólogo por Echeverría hay inconsistencias respecto de la jerarquía relativa que ocupan estos propósitos (normativo vs. descriptivo), pero hay más datos para pensar en una preeminencia de lo normativo (proscriptivo-prescriptivo) que de lo descriptivo. Hemos identificado el "exhibir" como la operación didáctica fundamental de Voces usadas en Chile, operación que hemos interpretado como dotada de ribetes más denunciatorios que meramente científicos. Esto, a pesar de que pueda identificarse un carácter más técnico en comparación con las obras normativas precedentes.

La manifestación más evidente de la índole normativa del trabajo de Echeverría son las categorías lexicológicas, tales como neologismo, chilenismo, barbarismo, etc., hacia las cuales hemos podido observar actitudes manifestadas a veces explícitamente y otras veces evidenciadas de manera implícita a través de ciertas prácticas discursivas, tales como los tipos de definiciones usadas en los artículos lexicográficos. Mientras hay algunas categorías que son objeto de actitudes positivas, tales como los neologismos, otras son valoradas negativamente, tales como los barbarismos. Las categorías que aluden a factores de diferenciación geolingüísticas, esto es, americanismos y chilenismos, no muestran un panorama claro. Más relevante que el uso de ciertos vocablos en una región geográfica determinada, parece importarle a Echeverría la cultura y la condición social de quienes los emplean típicamente. Y, en este punto, coincide con Ramón Sotomayor Valdés, Zorobabel Rodríguez y varios otros que defendían el principio del consensus eruditorum, que se remonta a Quintiliano y que fue revitalizado en Chile por Andrés Bello. Asoma en Echeverría una especie de visión democrática del lenguaje: Ios americanos también tienen derecho a intervenir y decidir en asuntos idiomáticos, y no solo los españoles. Sin embargo, es más bien "seudodemocrática", pues son solo algunos americanos y chilenos, los cultos, quienes gozan de este privilegio. Los chilenismos y americanismos usados por la gente culta, entonces, son aceptables normativamente, mientras que los chilenismos y americanismos vulgares no lo son. La frase de Echeverría que ya hemos citado es extremadamente clara al respecto: "El vulgo jamás podrá dar el tono de un idioma”.

Además de en el antipopulismo que acabamos de señalar, la ideología lingüística de Echeverría, que sustenta las actitudes ya señaladas, coincide en varios otros puntos con las de autores anteriores. Uno de estos puntos es la autoridad lingüística que la RAE tiene para el autor. Voces usadas en Chile tiene como una de sus finalidades apuntar voces con las que completar el Diccionario "oficial": se inscribe, de esta manera, en la lexicografía "academiocentrista". Sabemos a ciencia cierta que Echeverría consultaba constantemente el DRAE, tanto porque aparece en su bibliografía como porque lo declara abiertamente en el prólogo, así como por las observaciones contrastivas que incluyó en algunas de sus definiciones, las que establecen un diálogo intertextual evidente con la obra académica. Nótese, por otra parte, que ideas como la del progreso sometido al orden, orden encarnado en una serie de "reglas" del idioma, también aparece en 
la obra de Echeverría. Quizá más novedosa, en el contexto chileno de la época, es la aparición de una metáfora biológica para referirse a la evolución del lenguaje, aunque siempre vinculada con el orden social.

Un aspecto innovador en la obra de Echeverría es que, si uno de sus horizontes normativos es la institución académica española, el otro lo constituye la ciencia, encarnada en la Universidad de Chile, que centralizaba los estudios del lenguaje que podrían considerarse, hasta cierto punto, "científicos". La figura de Rodolfo Lenz, en concreto, representa la legitimación que Echeverría busca para su obra, lo cual explica la solicitud de cooperación que le extiende y la insistencia con que buscó su orientación y aprobación. Valdría la pena indagar en el futuro, en este sentido, hasta qué punto Echeverría podría ser considerado representativo de una etapa de transición en la institucionalización de los estudios científicos del lenguaje en Chile.

Sin embargo, creemos que la convivencia de aspectos normativos y descriptivos (por ejemplo, la inclusión de léxico tabuizado) se da con continuos solapamientos $y$, en el resultado mismo que es el libro, se manifiesta como una naturaleza inorgánica, no resuelta de manera cabal por el propio autor. La naturaleza heteróclita de Voces usadas en Chile, en este respecto, puede explicar la recepción negativa que, como han mostrado Rojas y Avilés (2012), tuvo entre sus contemporáneos.

\section{Bibliografía citada}

Alfero, Daniela, José J. Atria y Enrique Sologuren, 2008: "Lexicografía chilena finisecular. Voces usadas en Chile de Aníbal Echeverría y Reyes (1900)”, Onomázein 18, 113-137.

Araneda, Fidel, 1976: La Academia Chilena correspondiente de la Real Española e integrante del Instituto de Chile, Santiago: Editorial Universitaria.
Avilés, Tania y Darío Rojas, 2014: "Argumentación y estandarización lingüística: creencias normativas en el Diccionario de chilenismos (1875) de Zorobabel Rodríguez", Revista Signos. Estudios de Lingüística 85, 142-163.

Becerra, Yanira, Verena Castro y Claudio Garrido, 2007: Tres repertorios léxicos diferenciales del español de Chile en el s. XIX. Un estudio metalexicográfico. Tesis de licenciatura, Universidad de Chile.

BELLO, Andrés, 1847: Gramática de la lengua castellana destinada al uso de los americanos, Santiago: Imprenta del Progreso.

Bernaschina, Vicente, 2013: "Rodolfo Lenz, 150 años en disputa con el imperio de la lengua”, Universum 28(2), 117-138.

Bustos Plaza, Alberto y Herbert Ernst Wiegand, 2005-2006: "Condensación textual lexicográfica: esbozo de una concepción integral", Revista de Lexicografía XII, 7-46.

Brnon, Theodora, 2001: "The Synthesis of Comparative and Historical Indo-European Studies: August Schleicher" en Sylvain Auroux, Ernst F. K. Koerner, Hans-Josef Niederehe y Kees Versteegh (eds.): History of the Language Sciences / Geschichte der Sprachwissenschaft / Histoire des ciences du langage, vol. 2, Berlin / New York: Walter de Gruyter, 1223-1239.

ChÁvez, Soledad, 2009: Diccionarios del español de Chile en su fase precientífica: un estudio metalexicográfico. Tesis de maestría, Universidad de Chile.

Chávez, Soledad, 2010: "Ideas lingüísticas en prólogos de diccionarios diferenciales del español de Chile. Etapa 1875-1928", Boletín de Filología XLV(2), 49-69.

Chuchuy, Claudio, 1994: "Rasgos contrastivos y diferenciales en los diccionarios nacionales del español de América del siglo XIX" en Gerd Wotjak y Klaus Zimmermann (eds.): Unidad y variación lé- 
xicas del español de América, Frankfurt/Madrid: Vervuert/Iberoamericana, 83-103.

Echeverría y Reyes, Aníbal, 1900: Voces usadas en Chile, Santiago: Imprenta Elzeviriana.

Feliú CRUz, Guillermo, 1969: Aníbal Echeverría y Reyes (1864-1938), Santiago, Chile.

Ferreccio, Mario, 1979: "Las fuentes de la filología chilena. I. El catálogo anónimo de 1843”, Atenea 440, 39-59.

Gormaz, Valentín, 1860: Correcciones lexigráficas sobre la lengua castellana en Chile, Valparaíso: Imprenta del Comercio.

Kroskrity, Paul V., 2010: "Language ideologies Evolving perspectives" en Jürgen JASPERS, Jan-Ola Östman y Jef Verschueren (eds.): Society and Language Use, Amsterdam/Philadelphia: John Benjamins, 192-211.

LeNz, Rodolfo, 1894a: "De la ortografía castellana", Anales de la Universidad de Chile LXXXVII, 559-569.

LeNZ, Rodolfo, 1894b: "Apuntaciones para un testo de ortolojía y ortografía de la lengua castellana”, Anales de la Universidad de Chile LXXXVIII, 117-136.

Lenz, Rodolfo, 1987 [1905-1910]: Diccionario etimológico de las voces chilenas derivadas de lenguas indígenas americanas. Edición de Mario Ferreccio, Santiago: Universidad de Chile.

Matus, Alfredo, 1994: "Períodos en la lexicografía diferencial del español de Chile" en Actas del X Congreso de la Asociación de Academias de la Lengua Española, Madrid: Real Academia Española/ Espasa-Calpe, 189-199.

Milroy, James, 2001: "Language ideologies and the consequences of standardization", Journal of Sociolinguistics 5(4), 530-555.

Moré, Belford, 2004: “La construcción ideológica de una base empírica: selección y elaboración en la gramática de Andrés Bello" en José DEL VAlle y Luis Gabriel-Stheeman (eds.): La batalla del idioma. La intelectualidad hispánica ante la lengua, Frankfurt/Madrid: Vervuert/Iberoamericana, 67-92.

Ortúzar, Camilo, 1893: Diccionario manual de locuciones viciosas y de correcciones del lenguaje con indicación del valor de algunas palabras y ciertas nociones gramaticales, San Benigno Canavese: Imprenta Salesiana.

Paulsen, Fernando, 1876: Reparo de reparos, o sea, ligero examen de los "Reparos al "Diccionario de Chilenismos" de don Zorobabel Rodríguez», por don Fidelis P. del Solar. Santiago, Chile.

Rodriguez, Zorobabel, 1875: Diccionario de chilenismos, edición facsímil, Valparaíso: Imprenta de "El Independiente".

Rojas, Darío, 2010: "Estandarización lingüística y pragmática del diccionario: forma y función de los 'diccionarios de provincialismos' chilenos", Boletín de Filología XLV(1), 209-233.

Rojas, Darío, 2011a: "Voces usadas en Chile (1900): las cartas de Aníbal Echeverría y Reyes a Rodolfo Lenz, Onomázein 24, 349-361.

Rojas, Darío, 2011b: "Indicaciones contrastivas en Voces usadas en Chile (1900) de Aníbal Echeverría y Reyes", Revista Argentina de Historiografía Lingüística 3(1), 67-77.

Rojas, Darío, 2014: "Diccionario y estandarización lingüística en Hispanoamérica: la visión de Ramón Sotomayor Valdés (1866)", Estudios Filológi$\cos 53,109-121$.

Rojas, Darío y Tania Avilés, 2012: "La recepción de Voces usadas en Chile (1900) de Aníbal Echeverría y Reyes entre sus contemporáneos", Boletín de Filología XLVII(2), 149-175.

Rojas Carrasco, Guillermo, 1940: Filología chilena. Guía bibliográfica y crítica, Santiago: Universo.

Sand, Louis, 1958: The Role of Federico Hanssen and Rodolfo Lenz in the Intellectual Life of Chile. 
Tesis de doctorado, Universidad de Carolina del Norte.

Seco, Manuel, 2003: "El diccionario sincrónico del español” en Estudios de lexicografía española, Madrid: Gredos, 416-438.

Solar, Fidelis del, 1876: Reparos al "Diccionario de chilenismos" del señor don Zorobabel Rodríguez, Santiago: Imprenta de Federico Schrebler.

SwIGGers, Pierre, 2011: "19th century linguistics: practice and theory" en Bernd Kortmann y Johan Van der Auwera (eds.): The languages and linguistics of Europe: a comprehensive guide, Berlin/ Boston: Walter de Gruyter, 805-820.

SwIGgers, Pierre, 2012: "Linguistic historiography: object, methodology, modelization", Todas as Letras 14(1), 38-53. 